\title{
Personality Factors, Affect, and Autonomy Support as Predictors of Life Satisfaction
}

\author{
Factores de personalidad, afecto y soporte como \\ predictores de satisfacción de vida
}

Recibido: enero 13 de 2011 | Revisado: octubre 11 de 2011 | Aceptado: marzo 19 de 2012

\author{
Rogelio Puente DíAz* \\ Universidad Anáhuac, México \\ Judith Cavazos ARroyo** \\ Universidad Popular Autónoma \\ del Estado de Puebla, México
}

Para citar este artículo: Puente-Díaz, R. \& Cavazos, J. (2013). Personality factors, affect, and autonomy support as predictors of life satisfaction. Universitas Psychologica, 12(1), 41-53.

* Profesor-Investigador de Mercadotecnia-Comportamiento del consumidor.E-mail: rogelio.puente@ anahuac.mx

*** E- mail: judith.cavazos@upaep.mx

\section{A B S T R A C T}

This research examined the predictors of subjective well-being. Two studies were conducted. Our first study involved the administration of life satisfaction, personality, affection, need satisfaction, and self-construal questionnaires to 369 college students from Mexico. The results showed that extroversion and neuroticism had a significant direct effect on positive and negative affect, respectively, and indirect effects on life satisfaction. Results also revealed that autonomy support, defined as the ability to perceive oneself as the source of one's behavior, was a significant and positive predictor of life satisfaction. To address some of the limitations from study I, study II used the World Values Survey to examine the effects of autonomy support on life satisfaction and domain satisfaction among representative samples from Mexico, Argentina, and Brazil. The findings showed that the autonomy support was a significant predictor of life satisfaction and domain satisfaction in all three countries. The implications of the results are discussed.

Key words authors

Subjective well-being, life satisfaction, personality factors, autonomy support.

Key words plus

Psychometry, Quantitative Psychology, Mexico.

\section{RES U MEN}

Esta investigación examinó los predictores de bienestar subjetivo. Dos estudios fueron llevados a cabo. El primer estudio se administraron cuestionarios de satisfacción de vida, personalidad, afecto, necesidad de satisfacción y auto-constructo a 369 estudiantes de secundaria de México. Los resultados mostraron que la extroversión y el neuroticismo tienen un efecto directo sobre el afecto positivo y negativo, respectivamente, y efectos indirectos sobre la satisfacción de vida. Los resultados también revelan que el soporte, definido como la habilidad para percibirse a uno mismo como una fuente del propio comportamiento, se mostró como un predictor significativo y positivo de la satisfacción de vida. Para abordar algunas limitaciones del estudio I, el estudio II utilizó la Encuensta Mundial de Valores para examinar los efectos del soporte sobre la satisfacción de vida y la satisfacción de dominio entre muestras representativas de México, Argentina y Brazil. Los hallazgos mostraron que el soporte fue un predictor significativo de la satisfacción de vida y satisfacción de dominio en los tres países. Se discuten las implicaciones de los resultados.

Palabras claves autores

Bienestar subjetivo, satisfacción de vida, factores de personalidad, soporte.

Palabras clave descriptores

Psicometría, Psicología cuantitativa, México. 
The research on predictors and the consequences of people's subjective well-being has increased substantially in recent years. Some researchers suggest that there is not a more important variable to understand in social sciences that subjective well-being (SWB) (Helliwell \& Putnam, 2004). Regarding the predictors of subjective well-being, researchers have increasingly paid closer attention to differences between countries holding primarily a collectivistic vs. an individualistic mindset (Diener \& Tov, 2007). The conclusion so far is that there are more questions to be answered than answers to the current questions. For example, while some research suggests that affect influences the cognitive part of the subjective well-being, others have found this effect to be stronger in individualistic countries (Schimmack, 2007). Similarly, some researchers have debated about the importance of perceived autonomy on subjective well-being among members from cultures holding primarily an individualistic vs. a collectivistic mindset (Chirkov, 2007). One limitation, however, is that recent literature reviews on culture and subjective well-being only include very few, if any, studies with samples from LatinAmerican countries (Diener \& Tov, 2007) and virtually ignore the efforts conducted and published in Latin American countries and journals (see, D'Anello, 2006, for three recent publications; Gomez, Villegas de Posada, Barrera \& Cruz, 2007; Inga-Aranda \& Vara-Horna, 2006; and Cuadra \& Florenzano, 2003, for a review article).

Given the current state of the art recently summarized (Diener $\&$ Tov, 2007), the purpose of the present research was twofold. First, we explored how personality factors, affect, and autonomy support impact life satisfaction among a sample of Mexican nationals and also assessed the mediating role of cultural variables such as self-construal, whether the self is defined independent or interdependently. Second, we analyzed data from the World Values Survey in order to assess the impact of autonomy support on life satisfaction and domain satisfaction with representative samples from Mexico, Argentina and Brazil. In order to accomplish our purposes, we first need to discuss briefly the recent explosion of research on subjective well-being.

\section{The Study of Subjective Well-Being}

Few research topics have attracted more attention from such a wide variety of academic disciplines than the investigation of subjective well-being. Economist, marketing experts and psychologists, among others, have, with their own theoretical perspectives, made significant contributions to the understanding of subjective well-being. For example, Helliwell and Putnam (2004), two economists, examined the role of the social context in life satisfaction and found strong support for the importance of social capital, strong family and friend ties, in the explanation of life satisfaction. Other economists have produced fascinating findings suggesting that the increase in income does not produce a lasting effect on subjective well-being (Easterlin, 2005), and about the importance of relative income and economic aspirations (Rojas, 2009). Marketing experts have examined the effect of different types of consumption, indicating a greater positive impact of the consumption of goods that are resistant to adaptation and are inherently evaluable (Hsee \& Tsai, 2008). Lastly, psychologists have investigated the interaction between personality, affect, need satisfaction and life-satisfaction, among other variables (Diener, Suh, Lucas \& Smith, 1999; Deci \& Ryan, 2000).

The wide variety of research approaches and findings have led researchers to propose that people's subjective well-being is determined by three major factors: 1) stable differences, which include personality factors, 2) life circumstances, which include income levels and autonomy supportive environments, and 3) intentional activities, which involve engaging in activities that people enjoy (Lyubomirsky, Sheldon \& Schkade, 2005). Our research focuses on understanding the role of personality factors, affect and autonomy support as predictors of life satisfaction, with an emphasis on testing some hypotheses generated in the study of the interaction between personality, perceived autonomy, subjective well-being, and cultural variables. What follows is a review of the relevant literature on the predictors of subjective well-being. 


\section{Personality and Affect}

Most researchers agree that subjective well-being has three components. The cognitive component refers to an assessment of one's overall satisfaction with life, while the second and third components refer to the presence of positive affect and the absence of negative affect. The structure of subjective well-being appears to be consistent across different countries (Diener \& Tov, 2007). The personality traits of extraversion and neuroticism are two important and consistent predictors of subjective well-being. However, there is some controversy as to whether extroversion and neuroticism influence all three components equally. One proposition suggests that personality factors should have a stronger effect on the affective than on the cognitive component of subjective well-being (Schimmack, Diener $\&$ Oishi, 2002). This proposal also suggests that the effect of personality factors on the cognitive component of subjective well-being (SWB) is mediated by affect. Thus, it appears that positive and negative affect are influenced by personality factors, and that positive and negative affect have an impact on the cognitive component of subjective well-being, suggesting an indirect effect of personality factors.

As regards to the role of cultural variables, a proposition states that the effect of affect on the cognitive component of subjective well-being is stronger in individualistic than collectivistic countries (Schimmack, Oishi, Radhakrishnan, Dzokoto \& Ahadi, 2002). It is important to note that the moderating effect of culture on the relationship between affect and life satisfaction was tested with participants from different cultures that, supposedly, represent collectivistic and individualistic mindsets. Thus, individual differences in whether the self is defined interdependently, collectivism, or independently, individualism, were not actually measured, which might represent a limitation (Oyserman \& Lee, 2008). It is also possible to think that cultural variables such as self-construal might act as mediators, if measured at the individual level within in a single country. Thus, research findings on the interplay between personality, positive and negative affect, satisfaction with life and cultural variables has provided us two testable hypotheses:
H1: The effect of extroversion and neuroticism on satisfaction with life is mediated by positive and negative affect.

H2: The effect of positive and negative affect on satisfaction with life is mediated by independent self-construal ${ }^{1}$.

\section{Psychological Needs}

Self-Determination Theory (SDT) suggests that psychological growth and optimal levels of subjective well-being depend on the satisfaction of three innate psychological needs: autonomy, competence, and relatedness (Ryan \& Deci, 2002). Recently, there has been some controversy regarding the role of autonomy support in more collectivistic cultures due to the emphasis placed on defining the self interdependently as opposed to independently (Chirkov, 2007). SDT proposes that the need of autonomy is a universal need, but recognizes that there might be cultural differences in how individuals from different cultures try to satisfy this need (Ryan \& Deci, 2002).

Even though most investigations on the importance of autonomy support have been conducted in Western countries such as the US and Canada, some researchers have assessed the importance of the need of autonomy for optimal functioning in other cultures. For example, two investigations hypothesized mean differences in perceived autonomy support, but similar positive effects on subjective well-being among Brazilians, Russians, Americans and Canadians (Chirkov \& Ryan, 2001; Chirkov, Ryan \& Willness, 2005). The results from both studies found the expected mean differences, Americans and Canadians perceiving more autonomy support, and the positive effect of autonomy support on subjective well-being in all four countries. Thus, we might conclude that cultures might support autonomy differently or to more or less extent, but the positive effect of perceived autonomy

1 One of the reviewers raised a very important concern: whether self-construal should be treated as a mediator or a moderator. We reviewed the relevant literature on methodology (Baron \& Kenny, 1986) and also some relevant literature on cultural and cross-cultural psychology (Benet-Martinez \& KarakitapogluAygün, 2003; Matsumoto \& Hee-Yoo, 2006) and decided that the conceptualization of self-construal as a mediator was appropriate. We thanked the reviewer for challenging our thinking. 
appears to be invariant across cultures. In order to try to clarify the role of autonomy support on life satisfaction, we explored the impact of interdependent self-construal as a possible mediator and also whether the suggested positive impact of autonomy support is consistent across three countries that are thought as collectivistic. If the propositions set by SelfDetermination Theory are right, then we would find a non-significant effect of interdependent self-construal and we would find a positive effect of autonomy support on life satisfaction across countries. Thus, the following hypotheses were formulated:

H3: The effect of autonomy support on satisfaction with life is mediated by the individual levels of interdependent self-construal.

H4: Autonomy support will have a positive effect on life satisfaction and domain satisfaction significantly across participants from Mexico, Argentina, and Brazil.

On a recent article (Heine \& Ruby, 2010), researchers criticized the excessive use of western samples in most psychological research because it limits our ability to have a more comprehensive understanding of relevant psychological phenomena. Research on subjective well-being is not exempt of this criticism. Yet, it is important to acknowledge that research on subjective well-being published in Latin-American journals and conducted with nonwesterns samples is relatively scant.

In one of these investigations, researchers examined the predictors of life satisfaction among older adults in Peru. The results showed that some of the strongest predictors of life satisfaction were social support and number of close friends (Inga-Aranda $\&$ Vara-Horna, 2006), lending support to the importance of social capital (Helliwell \& Putnam, 2004). Similarly, another investigation explored the motivational predictors of subjective well-being (Martin-Albo, Nuñez, Navarro \& Grijalvo, 2009). Results from this investigation showed that social self-concept and intrinsic motivation were two of the strongest predictors of subjective well-being.

Given the importance of understanding the predictors of subjective well-being in Latin-American countries, we conducted two studies. The purpose of study I was to test the impact of personality factors, affect, and autonomy support on life satisfaction and the mediating role of self-construal among participants from Mexico. Similarly, the purpose of study II was to examine the impact of autonomy support on life satisfaction and domain satisfaction among representative samples of participants from Mexico, Argentina and Brazil using the World Values Survey as a source of information. What follows is an explanation of the methodology for Study I in which the first three hypotheses were tested.

\section{Method: Study I}

\section{Participants}

369 college students from Mexico City and Puebla were the participants (53\% females and $47 \%$ males). Participants' ages ranged from 17 to 63 years $(\mathrm{M}=21.79)$.

\section{Measures}

Big Five Inventory (BFI) (Benet-

Martínez E John, 1998)

This measure uses 44 short phrases to assess extraversion, agreeableness, conscientiousness, neuroticism, and openness to experience. Respondents rated each of the 44 short phrases on a 5-point scale ranging from 1 (strongly disagree) to 5 (strongly agree). For the purpose of our statistical analysis, we used an abbreviated scale, four items for each variable, to measure extraversion and neuroticism. The scale showed adequate psychometric properties for scientific research (e.g., significant loadings and coefficients of internal consistency above 0.65).

The Satisfaction with Life Scale (SWLS) (Diener, Emmons, Larsen, Eु Griffin, 1985)

The SWLS is a 5-item questionnaire designed to measure life satisfaction. The questionnaire uses a Likert-type scale and total scores range from 5 to 35 . The scale showed adequate psychometric properties for scientific research (e.g., significant loadings and a coefficient of internal consistency of 0.84 ). 


\section{General Need Satisfaction Scale (Gagné, 2003)}

This scale was adapted based on Self-Determination Theory by Gagné (2003) and uses 21 items to measure need satisfaction. Respondents indicated on a scale from 1 (not true at all) to 7 (definitely true) the extent to which the psychological needs of autonomy, relatedness, and competence are generally satisfied in their lives. For the purpose of our statistical analysis, we used an abbreviated scale, three items, in order to assess autonomy support. The abbreviate scale showed adequate psychometric properties (e.g., significant loadings and a coefficient of internal consistency of 0.6).

\section{The Positive Affect and Negative Affect Scale} (PANAS) (Watson, Clark, EB Tellegen, 1988)

The PANAS is a 20 -item measure that assesses positive (10 items) and negative affect (10 items). The PANAS uses a five-point Likert-type scale, ranging from 10 (very low) to 50 (very high). For the purpose of our statistical analysis, we used an abbreviated scale, four items for each variable, in order to measure positive and negative affect. The scale showed adequate psychometric properties for scientific research (e.g., significant loadings and coefficients of internal consistency above 0.75 ).

\section{Independent-Interdependent Self- \\ Construals (Singelis, 1994)}

This measure was used in order to assess independent and interdependent self-construal with 12 items each. This measure uses a seven-point Likert-type scale. For the purpose of our statistical analysis, we used an abbreviated scale, six items for each variable, to measure independent and interdependent self-construal. The scale showed adequate psychometric properties for scientific research (e.g., significant loadings and coefficients of internal consistency above 0.6).

Procedure

Participants completed the questionnaire packets individually. Participants were informed that all data would be anonymous and strictly confidential, available only to the researcher. Questionnaires were completed within 30 minutes. Our investigation received the approval from the internal human subject committee.

\section{Results}

We used Structural Equation Modeling (SEM) with LISREL 8.80 to test our hypotheses. Since all questionnaires were developed and tested with English speaking participants, we first conducted Confirmatory Factor Analysis (CFA) to assess their psychometric properties. The results showed that all model fits were acceptable and that all factor loadings were significant. The decision not to use the complete scales was made in order to save degrees of freedom to test our full structural model, measurement and latent model. In order to assess the robustness of the different models, we used a combination of absolute and incremental fit index. Thus, we report the $\chi^{2}$, Root Mean Square Error of Approximation (RMSEA), and the Incremental Fit Index (IFI) for each of the analysis conducted. We always report the standardized coefficients.

\section{Hypotheses I and II}

Hypothesis I suggests that the effects of extroversion and neuroticism on life satisfaction are mediated by positive and negative affect. In order to test mediation effects with Structural Equation Modeling, quantitative methodologists (Little, Card, Bovaird, Preacher \& Crandall, 2007; Preacher \& Hayes, 2008) suggest to conduct the following procedure: we first fitted to an unrestricted model allowing extroversion and neuroticism to directly affect life satisfaction and then fitted a second model, the mediation or restricted model, in which the effects of extroversion and neuroticism were mediated by positive and negative affect. In order to establish mediation, we need to find, in the unrestricted model, that: the direct effects of extroversion and neuroticism on life satisfaction are not significant, that the effects of extroversion and neuroticism on positive and negative affect are significant, and that the effects of positive 
and negative affect on life satisfaction are significant as well. Regarding the restricted model, we need to find that the overall fit of the model is acceptable with the restriction of not allowing a direct effect of extroversion and neuroticism on life satisfaction and that the indirect effects of extroversion and neuroticism on life satisfaction are significant.

The results from the first model showed an acceptable model fit $\chi^{2}=613.38, p=0.00(d f=182)$, RMSEA $=0.08$ and IFI $=0.91$. Results from the latent model revealed that the direct effects of extroversion and neuroticism on satisfaction with life were not significant $(\gamma=-0.09, p>0.05 ; \gamma=0.04$, $p>0.05$, respectively). Conversely, the effect of extroversion on positive affect and neuroticism on negative affect were significant $(\gamma=0.48, p<0.05$; $\gamma=0.55, p<0.05$, respectively). Lastly, the effects of positive and negative affect on life satisfaction were significant and in the expected direction $(\beta=0.53$, $p<0.05 ; \beta=-0.22, p<0.05$, respectively).

We next conducted our second analysis in which we restricted extroversion and neuroticism to only have a direct effect on positive and negative affect. The results showed an acceptable and almost identical model fit $\chi^{2}=616.05, p<0.01(d f=184)$, RMSEA $=0.08$ and IFI $=0.91$. The difference chisquare test was not significant $\left(\Delta \chi^{2}=2.67, d f=2\right.$, $p>0.05)$, thus constraining the direct effects of extroversion and neuroticism on life satisfaction to be zero did not affect the model fit significantly. The examination of the individual parameters showed that the effect of extroversion on positive affect and neuroticism on negative affect were significant $(\gamma=0.47, p<0.05 ; \gamma=0.54, p<0.05$, respectively $)$ and that the effects of positive and negative affect on life satisfaction were also significant and in the expected direction $(\beta=0.48, p<0.05 ; \beta=-0.19$, $p<0.05$, respectively). Lastly, the indirect effects of extroversion and neuroticism on life satisfaction were significant and in the expected direction $(0.22, \&-0.10, p<0.05$, respectively), lending evidence for the hypothesized mediation effects.

Hypothesis II proposes that the effects of positive and negative affect on life satisfaction are mediated by independent self-construal. We followed the same analytical strategy, as before, to test for mediation.
Results from the full model showed an acceptable model fit $\chi^{2}=254.60, p=0.01(d f=146)$, RMSEA $=0.04$ and IFI $=0.97$. Results from the latent model revealed that the effects of positive and negative affect on life satisfaction were significant $(\gamma=0.43, p<0.05 ; \gamma=-0.14, p<0.05)$. The effect of positive affect on independent self-construal was significant $(\gamma=0.51, p<0.05)$, whereas the effect of negative affect was not $(\gamma=-0.14, p>0.05)$. Lastly, the effect of independent self-construal on life satisfaction was not significant $(\beta=0.11, p>0.05)$. Given that the hypothesized mediator, independent self-construal, did not have a significant effect on life satisfaction and that positive and negative affect did have a significant direct effect on life satisfaction, the requirements to establish mediation were not met (Little et al., 2007). Thus, we did not conduct the second analysis, testing the mediation model.

\section{Hypotheses III}

Hypothesis III suggests that the effect of autonomy support on life satisfaction is mediated by interdependent self-construal. We followed the same analytical strategy. The results from the full model showed an acceptable model fit $\chi^{2}=148.66$, $p<0.01(d f=74)$, RMSEA $=0.05$ and IFI $=0.96$. The examination of the individual parameters revealed that the direct effects of autonomy support on interdependent self-construal and satisfaction with life were significant $(\gamma=0.53, p<0.05$; $\gamma=0.56, p<0.05$, respectively). Conversely, the effect of interdependent self-construal on life satisfaction was not significant in this model $(\beta=0.12$, $p>0.05)$. Since one of the requirements to establish mediation is that the mediator, interdependent self-construal, needs to have a significant effect on the dependent variable (Little et al., 2007), life satisfaction, we did not run the mediation model and concluded that autonomy support affects satisfaction with life directly.

\section{Integrated model}

Lastly, we conducted an additional analysis integrating findings from our three previous hypotheses 


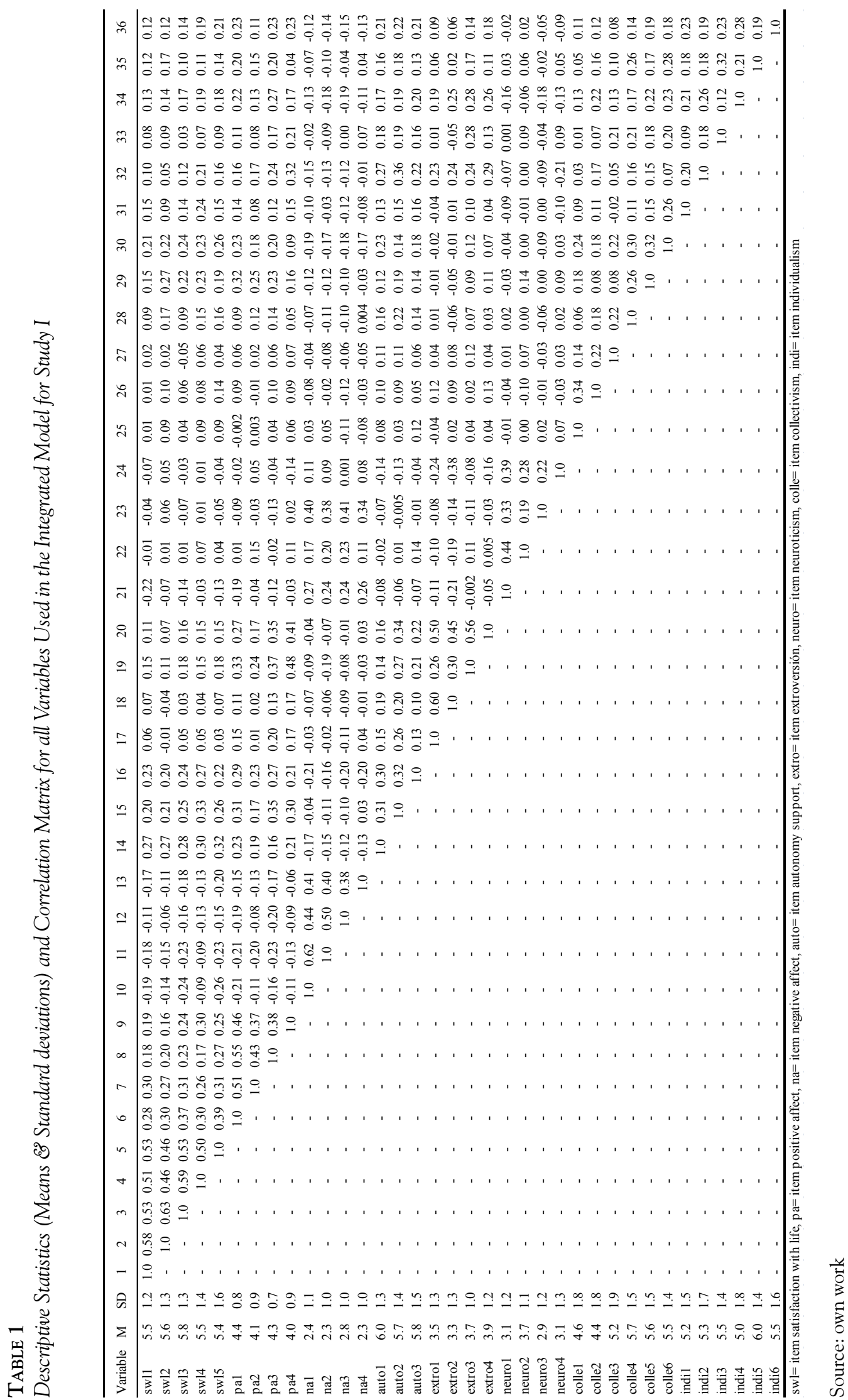

\begin{tabular}{|l|l|l|l|l|} 
Universitas Psychologica | V. 12 & No. 1 & enero-marzo | & 2013
\end{tabular} 


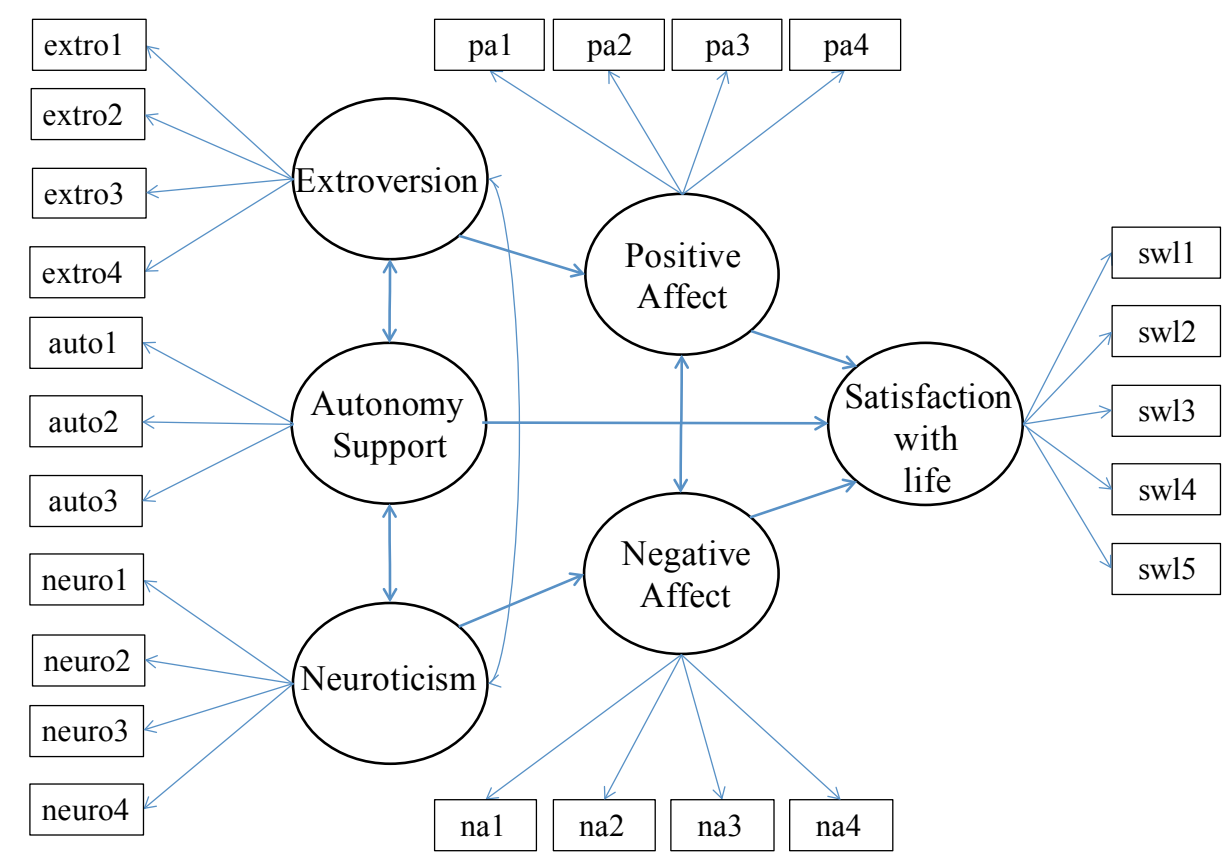

Figure 1. Hypothesized Integrated Model for Study I.

Source: Own work.

into a single model (see Table 1 for descriptive statistics and Figure 1 for the hypothesized integrated model). The results showed an acceptable model fit $\chi^{2}=786.72, p<0.01(d f=244)$, RMSEA $=0.08$ and IFI $=0.91$. The examination of the individual parameters revealed that extroversion and neuroticism had a significant effect on positive and negative affect $(\gamma=0.51, p<0.05 ; \gamma=0.55, p<0.05$, respectively). Similarly, autonomy support and positive and negative affect had a significant effect on life satisfaction $(\gamma=0.33, p<0.05 ; \beta=0.33, p<0.05$; $\beta=-0.16, p<0.05$, respectively). The indirect effects of extroversion and neuroticism on life satisfaction were also significant $(0.17 \&-0.09, p<0.05$, respectively). Lastly, squared multiple correlations for the endogenous variables were, respectively, life satisfaction (0.33), positive affect $(0.26)$, and negative affect (0.3).

\section{Discussion}

Our first study tested three hypotheses. We found that the effects of extroversion and neuroticism on life satisfaction were mediated by positive and negative affect, supporting hypothesis I. This is consistent with other investigations (Schimmack et al., 2002).

Hypotheses II proposed that the effects of positive and negative affect were mediated by independent self-construal. We did not find support for the role of independent self-construal as a mediator of the effects of positive and negative affect on life satisfaction. Other investigations have suggested that positive and negative affect have a stronger effect on life satisfaction in countries thought to be more individualistic than collectivistic. We did not find differences in independent self-construal to mediate the effect of positive and negative affect on life satisfaction.

Lastly, we tested whether the effects of autonomy support were mediated by interdependent self-construal. We did not find support for this hypothesis. Autonomy support was a strong predictor of life satisfaction regardless of levels of interdependent self-construal, which is consistent with the universality of the importance of autonomy support (Ryan \& Deci, 2002).

Our first study had the limitation that we used a sample of college students. Thus, we decided to use a public source of data to explore the impor- 
tance of autonomy support in three Latin-America countries. Study II, then, tried to further validate the importance of autonomy support with more representative samples.

\section{Method: Study II}

\section{Participants}

We used the World Values Survey ([WVS], 2009) as our source of information. For the Mexican sample, participants were $1560,51 \%$ female, residents of Mexico with a mean age of 39.7 years. For the Argentinean sample, participants were $1002,53 \%$ females, with a mean age of 42.6 years. Lastly, in the Brazilian sample, participants were $1500,58 \%$ females, with a mean age of 40 years. All three samples were representative of the 18 an older population of each country.

\section{Measures}

The WVS measures different variables with representative samples of the general population in several countries. We focused on the last wave of data collection, 2005 and 2006, and on the information from three Latin-American countries: Mexico, Brazil and Argentina ${ }^{2}$. In order to assess all the relevant variables in our investigation, we used the following questions from the general questionnaire:

\section{Life Satisfaction}

We used two questions to measure life satisfaction: "How satisfied are you with your current life?" measured in a scale from 1 to 10 and "in general, how happy are you?" measured in a scale from 1 to 4 . We reversed the scores from the happiness questions so that high scores reflect high levels of happiness.

2 We wanted to include as many countries as possible from LatinAmerica. However, only these three countries had all the questions needed to measure life satisfaction, domain satisfaction, and autonomy support.

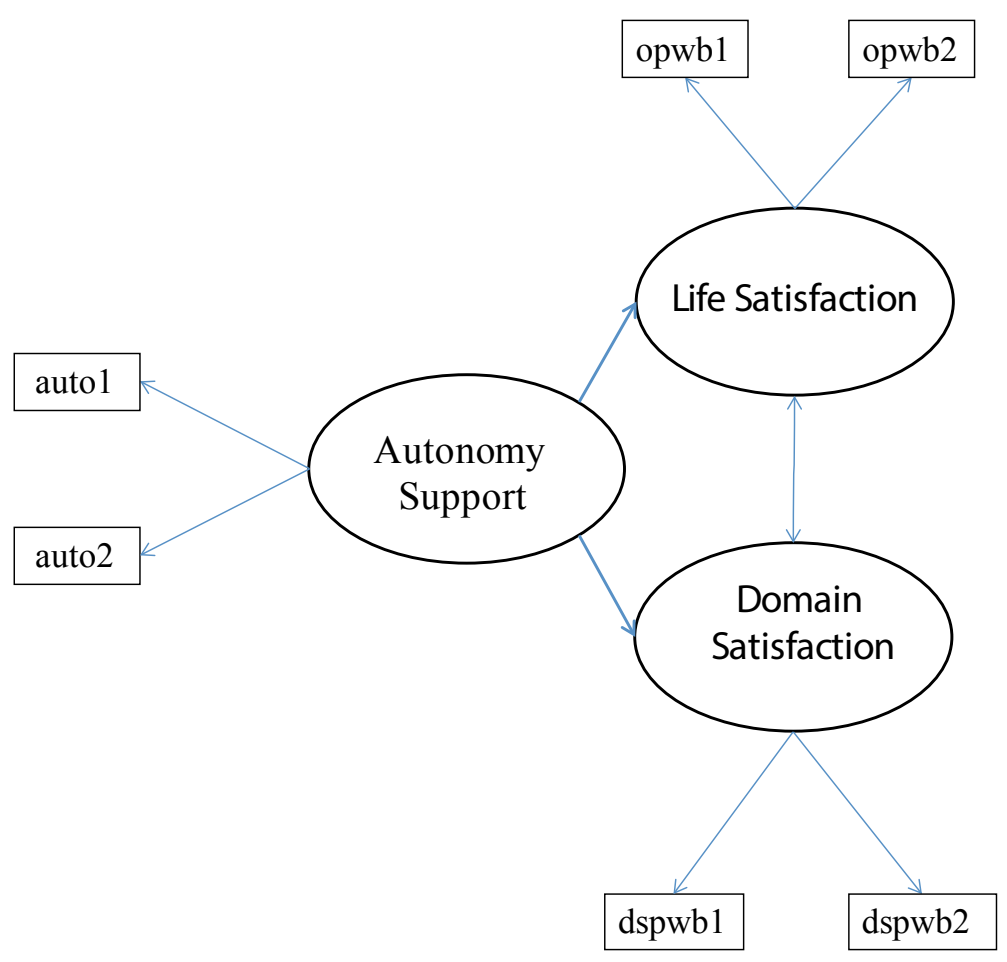

Figure 2. Hypothesized Model for Study II.

Source: Own work. 


\section{Domain Satisfaction}

For domain satisfaction, we used two questions from the general questionnaire: "How would you describe your current health?" measured in a scale from very good (1) to bad (4) and "how satisfied are you with the financial situation of your household"? measured in a scale from Completely Unsatisfied (1) to Completely Satisfied (10). We reversed the scores of the health question so high scores reflected a better perceived health. The assessment of both, life satisfaction and domain satisfaction, is consistent with other investigations (Schimmack, Diener et al., 2002).

\section{Autonomy Support}

We used, once again, two questions to measure perceptions of autonomy support: "How much freedom of choice and control do you feel you have over your life"? measured in a scale from Nothing (1) to Quite a lot (10) and "I decide by myself my goals in life" measured in a scale from Completely Agree (1) to Completely disagree (4). We reversed the scores from the goals question so that high scores reflected greater autonomy support to choose goals in life (See Figure 2 for the hypothesized model).

\section{Procedure}

Data collection in all three countries was conducted face to face. The questionnaires were administered in the native language of each country. Data collection took place in November and December of 2005 for the Mexican sample and in November and December 2006 for the Argentinean and Brazilian samples.

\section{Results}

Given that we were interested in examining the effect of autonomy support on life satisfaction and domain satisfaction across countries, we followed the analytical strategy proposed by Card and Little (in press) to examine the differences between countries and fitted two models to assess the measurement invariance. Once the measurement invariance is established, one can compare the size of the coefficients of interest. In the first analysis, we fitted an unrestricted model in which the factor loadings and intercepts were estimated within each culture. In the second analysis, we fitted a restricted model in which we restricted the factor loadings and intercepts to be equal across countries. Card and Little (in press) recommend using a modeling rationale to decide if the restricted model, the one that assumes measurement invariance, fits the data reasonably well. Establishing measurement invariance is a necessary condition to make comparisons across countries. We again assessed the robustness of the model using a combination of absolute and incremental fit index. Thus, we report the $\chi^{2}$, Root Mean Square Error of Approximation (RMSEA), and the Incremental Fit Index (IFI) and the standardized coefficients for each of the analysis conducted.

\section{Measurement Invariance}

Results from the unrestricted model showed an acceptable overall fit $\chi^{2}=177.40, p<0.01(d f=39)$, RMSEA $=0.05$ and IFI $=0.95$. All factor loadings were significant and in the expected direction. Similarly, the results from the restricted model also showed an acceptable fit $\chi^{2}=207.38, p=0.01$ $(d f=6)$, RMSEA $=0.05$ and IFI $=0.94$. As suggested by Card and Little (in press), if the restricted model shows an adequate fit (e.g., RMSEA $<0.08$ and CFI and IFI $>0.9$ ) then measurement invariance can be concluded. Given that we were able to find support for measurement invariance, we proceeded to test hypothesis IV.

\section{Hypothesis IV}

Hypothesis IV proposes that autonomy support affects life satisfaction and domain satisfaction significantly across participants from Mexico, Argentina, and Brazil. This hypothesis implies that the effect of autonomy support is significant across countries. However, we can also test if the size of the coefficients across countries is similar. In order to test this hypothesis, we used the same analytical strategy of fitting an unrestricted 
model first (allowing the gamma coefficients to be estimated within each culture) followed by restricted model (restricting the size of the coefficients to be equal across all three countries). The overall fit of the unrestricted model was acceptable $\chi^{2}=187.35$, $p=0.00(d f=36)$, RMSEA $=0.06$ and IFI $=0.95$. The examination of the individual parameters from the latent model showed a significant effect of autonomy support on overall life satisfaction for all three countries: Mexico, Argentina and Brazil $(\gamma=0.95$, $p<0.05 ; \gamma=0.94, p<0.05 ; \gamma=0.99, p<0.05$, respectively). Similarly, the results also revealed a significant effect of autonomy support on domain satisfaction $(\gamma=0.92, p<0.05 ; \gamma=0.88, p<0.05$; $\gamma=0.72, p<0.05$, respectively).

The results from the restricted model, using Mexico's model as a reference, also showed an acceptable model fit $\chi^{2}=241.77, p<0.01(d f=48)$, RMSEA $=0.06$ and IFI $=0.93$. Thus, restricting the coefficients to be equal across countries did not significantly affect the fit of the model. Consequently, we can conclude that the effect of autonomy support is significant and similar in magnitude across all three countries.

\section{Discussion}

The purpose of study II was to validate the importance of autonomy support with more representative samples. Our results showed that autonomy support had a significant effect on life satisfaction and domain satisfaction in all three countries, supporting Hypothesis IV. Thus, study II helped us to increase our confidence about the important role that autonomy support plays in the explanation of life satisfaction and domain satisfaction among members from three Latin-American countries.

\section{General Discussion}

The examination of the predictors of subjective well-being has increased dramatically in the last 10 years. However, this enthusiasm has not, to our knowledge, been as strong among Latin-American scholars. Our investigation attempted to make a contribution by testing some of the hypotheses gen- erated in the literature on the interplay between life satisfaction, personality, affect, autonomy support and cultural variables.

We found support for the differentiated role of personality factors in subjective well-being. Specifically, extroversion and neuroticism directly influenced the affective component of subjective well-being, positive and negative affect, and indirectly the cognitive component, life satisfaction. This is consistent with other investigations (Schimmack et al., 2002). In a recent chapter that examined the structure of subjective well-being (Schimmack, 2007), one proposition states that judgments of life satisfaction are informed by, among several factors, affect, and that positive and negative affect are influenced by personality factors. Thus, extroversion and neuroticism exert their influence on a reliable source of information such as affect that people use to make judgments about satisfaction with life (Schimmack et al., 2002).

We also found that positive and negative affect were strong life satisfaction predictors regardless of levels of independent self-construal. However, this alone does not rule out the role of cultural variables in affect. For example, a relatively new and very interesting line of research is exploring the concept of ideal vs. actual affect, its cultural causes and implications for behavior and subjective well-being (Tsai, 2007). The cultural differences in ideal affect and their effect on life satisfaction might represent an interesting line of research for the future.

Consistent with the propositions set by SelfDetermination Theory (Ryan \& Deci, 2002), autonomy support was a strong predictor of life satisfaction among college students and also among representative samples of the adult population from three Latin-American countries. Our results provide evidence to the universality of autonomy support and its relevance for psychological functioning. However, the role of cultural variables is still relevant since other investigations have found country differences in levels of autonomy support (Chirkov \& Ryan, 2001; Chirkov et al., 2005). Future investigations might also want to explore the differences in how autonomy is defined and perceived by members from different countries. 


\section{Limitations}

Our investigation had several limitations. First, study I used a sample of college students which might not represent well the adult population of Mexico. Thus, the results of our first study need to be interpreted with this limitation in mind. Study II provided some validity about the importance of autonomy support by using more representative samples. However, one limitation of public sources of data is that they often do not use the psychometrically valid scales developed to measure psychological variables. Yet, we strongly believe that the measures extracted from the World Values Survey database had acceptable psychometric properties and that the use of other sources of information to validate research findings represents a robust strategy regardless of the possible limitations of the instruments.

In sum, our investigation tried to make a contribution by testing some of the hypotheses generated in the literature on the interplay between life satisfaction, positive and negative affect, personality factors, autonomy support, interdependent and independent self-construal. Our results support the importance of extroversion, neuroticism, positive and negative affect, and autonomy support in the explanation of life satisfaction. As suggested earlier, subjective well-being is one of the most important variables to explain by social scientists and we hope this enthusiasm is shared by other researchers in Latin-America.

\section{References}

Baron, R. M. \& Kenny, D. A. (1986). The moderatormediator variable distinction in social psychological research: Conceptual, strategic, and statistical considerations. Journal of Personality and Social Psychology, 51(6), 1173-1182.

Benet-Martinez, V. \& John, O. P. (1998). Los Cinco Grandes across cultures and ethnic groups: Multitrait multimethod analyses of the Big Five in Spanish and English. Journal of Personality and Social Psychology, 75(3), 729-750.

Benet-Martínez, V. \& Karakitapoglu-Aygun, Z. (2003). The interplay of cultural values and personality in predicting life-satisfaction: Comparing Asian- and
European-Americans. Journal of Cross-Cultural Psychology, 34(1), 38-61.

Card, N. A. \& Little, T. D. (in press). Analytic considerations in cross-cultural research on peer relations. In X. Chen, D. C. French \& B. Schneider (Eds.), Peer relations in cultural context. New York: Cambridge University Press.

Chirkov, V. I. (2007). Culture, personal autonomy and individualism: Their relationships and implications for personal growth and well-being. In G. Zheng, K. Leung \& J. G. Adair (Eds.), Perspectives and progress in contemporary cross-cultural psychology (pp. 247-263). Beijing, China: China Light Industry Press.

Chirkov, V. I. \& Ryan, R. M. (2001). Parent and teacher autonomy-support in Russian and U.S. adolescents: Common effects on well-being and academic motivation. Journal of Cross-Cultural Psycho$\log y$, 32(5), 618-635.

Chirkov, V. I., Ryan, R. M. \& Willness, C. (2005). Cultural context and psychological needs in Canada and Brazil: Testing a self-determination approach to internalization of cultural practices, identity and well-being. Journal of Cross-Cultural Psychology, 36(4), 425-443.

Cuadra, H. \& Florenzano, R. (2003). El bienestar subjetivo: hacia una psicología positiva. Revista de Psicología de la Universidad de Chile, 12(1), 83-96.

D'Anello, S. (2006). Efecto de las normas y emociones en los juicios sobre satisfacción con la vida en una muestra venezolana. Interamerican Journal of Psychology, 40(3), 371-376.

Deci, E. L. \& Ryan, R. M. (2000). The 'what' and 'why' of goal pursuits: Human needs and the selfdetermination of behavior. Psychological Inquiry, 11(4), 227-268.

Diener, E., Emmons, R. A., Larsen, R. J. \& Griffin, S. (1985). The satisfaction with life scale. Journal of Personality Assessment, 49(1), 71-75.

Diener, E., Suh, E. M., Lucas, R. E. \& Smith, H. E. (1999). Subjective well-being: Three decades of progress. Psychological Bulletin, 125(2), 276-302.

Diener, E. \& Tov, W. (2007). Culture and subjective well-being. In S. Kitayama \& D. Cohen (Eds.), Handbook of cultural psychology (pp. 691-713). New York: Guilford. 
Easterlin, R. A. (2005). Building a better theory of wellbeing. In L. Bruni \& P. Porta (Eds.), Economics and Happiness (pp. 29-64). Oxford: Oxford UP.

Gagné, M. (2003). The role of autonomy support and autonomy orientation in prosocial behavior engagement. Motivation and Emotion, 27(3), 199-223.

Gomez, V., Villegas de Posada, C., Barrera, F. \& Cruz, J. E. (2007). Factores predictores de bienestar subjetivo en una muestra colombiana. Revista Latinoamericana de Psicología, 39(2), 311-325.

Heine, S. J., \& Ruby, M. B. (2010). Cultural psychology. Wiley Interdisciplinary Reviews: Cognitive Science, 1(2), 254-266.

Helliwell, J. F. \& Putnam, R. D. (2004). The social context of well-being. Philosophical Transactions of the Royal Society, 359(1449), 1435-1446.

Hsee, C. K. \& Tsai, C. (2008). Hedonomics in consumer behavior. In C. P. Haugtvedt, P. M. Herr \& F. R. Kardes (Eds.), Handbook of consumer psychology (pp. 639-658). Mahwah, NJ: Lawrence Erlbaum Associates.

Inga-Aranda, J. \& Vara-Horna, A. (2006). Factores asociados a la satisfacción de vida de adultos mayores de 60 años en Lima-Perú. Universitas Psychologica, 5(3), 475-485.

Little, T. D., Card, N. A., Bovaird, J. A., Preacher, K. J. \& Crandall, C. S. (2007). Structural equation modeling of mediation and moderation with contextual factors. In T. D. Little, J. A. Bovaird \& N. A. Card (Eds.), Modeling contextual effects in longitudinal studies (pp. 207-230). Mahwah, NJ: Lawrence Erlbaum Associates.

Lyubomirsky, S., Sheldon, K. M. \& Schkade, D. (2005). Pursuing happiness: The architecture of sustainable change. Review of General Psychology, 9(2), 111-131.

Martin-Albo, J., Nuñez. J. L., Navarro, J. G. \& Grijalvo, F. (2009). Un modelo motivacional explicativo del bienestar psicológico en la universidad. Revista Mexicana de Psicología, 26(1), 41-50.

Matsumoto, D. \& Hee-Yoo, S. (2006). Toward a new generation of cross-cultural research. Perspectives on Psychological Science, 1(3), 234-250.

Oyserman, D. \& Lee, S. W. S. (2008). Does culture influence what and how we think? Effects of pri- ming individualism and collectivism. Psychological Bulletin, 134(2), 311-342.

Preacher, K. J. \& Hayes, A. F. (2008). Contemporary approaches to assessing mediation in communication research. In A. F. Hayes, M. D. Slater \& L. B. Snyder (Eds.), The Sage sourcebook of advanced data analysis methods for communication research (pp. 13-54). Thousand Oaks, CA: Sage.

Rojas, M. (2009). Economía de la felicidad: hallazgos relevantes respecto al ingreso y el bienestar. $E l$ Trimestre Económico, 76(3), 537-573.

Ryan, R. M. \& Deci, E. L. (2002). An overview of SelfDetermination Theory: An organismic-dialectical perspective. In E. L. Deci \& R.M. Ryan (Eds), Handbook of Self-Determination Research. (pp.333). New York: The University of Rochester Press.

Schimmack, U. (2007). The structure of subjective well-being. In R. Larsen \& M. Eid (Eds.), The science of subjective well-being (pp. 97-123). New York: Guilford.

Schimmack, U., Diener, E. \& Oishi, S. (2002). Life satisfaction is a momentary judgment and a stable personality characteristic: The use of chronically accessible and stable resources. Journal of Personality, 70(3), 345-384.

Schimmack, U., Oishi, S., Radhakrishnan, P., Dzokoto, V. \& Ahadi, S. (2002). Culture, personality, and subjective well-being: Integrating process models of life satisfaction. Journal of Personality and Social Psychology, 82(4), 582-593.

Singelis, T. M. (1994). The measurement of independent and interdependent self-construals. Personality and Social Psychology Bulletin, 20(5), 580-591.

Tsai, J. L. (2007). Ideal affect: Cultural causes and behavioral consequences. Perspectives on Psychological Science, 2(3), 242-259.

Watson, D., Clark, L. A. \& Tellegen, A. (1988). Development and validation of brief measures of positive and negative affect: The PANAS Scales. Journal of Personality and Social Psychology, 54(6), 1063-1070.

World Values Survey Association. (2009). World Values Survey 1981-2008 (Official Aggregate v.20090901). Madrid: Aggregate File Producer: ASEP/JDS. Available at www.worldvaluessurvey.org 
